\title{
Synthesis and characterization of noble metal-titania core-shell nanostructures with tunable shell thickness
}

\author{
Bartosz Bartosewicz ${ }^{1}$, Marta Michalska-Domańska ${ }^{1}$, Malwina Liszewska1, \\ Dariusz Zasada ${ }^{2}$ and Bartłomiej J. Jankiewicz ${ }^{* 1}$
}

\author{
Full Research Paper \\ Address: \\ ${ }^{1}$ Institute of Optoelectronics, Military University of Technology, \\ Kaliskiego 2 Str. 00-908 Warsaw, Poland and ${ }^{2}$ Faculty of Advanced \\ Technologies and Chemistry, Military University of Technology, \\ Kaliskiego 2 Str. 00-908 Warsaw, Poland \\ Email: \\ Bartłomiej J. Jankiewicz* - bartlomiej.jankiewicz@wat.edu.pl \\ * Corresponding author \\ Keywords: \\ $\mathrm{Ag} @ \mathrm{TiO}_{2} ; \mathrm{Au} @ \mathrm{TiO}_{2}$; core-shell nanostructures; titania coating; \\ titanium dioxide; tunable resistive pulse sensing
}

Beilstein J. Nanotechnol. 2017, 8, 2083-2093. doi:10.3762/bjnano.8.208

Received: 18 May 2017

Accepted: 04 September 2017

Published: 05 October 2017

Associate Editor: N. Motta

(c) 2017 Bartosewicz et al.; licensee Beilstein-Institut. License and terms: see end of document.

\begin{abstract}
Core-shell nanostructures have found applications in many fields, including surface enhanced spectroscopy, catalysis and solar cells. Titania-coated noble metal nanoparticles, which combine the surface plasmon resonance properties of the core and the photoactivity of the shell, have great potential for these applications. However, the controllable synthesis of such nanostructures remains a challenge due to the high reactivity of titania precursors. Hence, a simple titania coating method that would allow better control over the shell formation is desired. A sol-gel based titania coating method, which allows control over the shell thickness, was developed and applied to the synthesis of $\mathrm{Ag} @ \mathrm{TiO}_{2}$ and $\mathrm{Au} @ \mathrm{TiO}_{2}$ with various shell thicknesses. The morphology of the synthesized structures was investigated using scanning electron microscopy (SEM). Their sizes and shell thicknesses were determined using tunable resistive pulse sensing (TRPS) technique. The optical properties of the synthesized structures were characterized using UV-vis spectroscopy. $\mathrm{Ag} @ \mathrm{TiO}_{2}$ and $\mathrm{Au} @ \mathrm{TiO}_{2}$ structures with shell thickness in the range of $\approx 40-70 \mathrm{~nm}$ and $90 \mathrm{~nm}$, for the $\mathrm{Ag}$ and $\mathrm{Au}$ nanostructures respectively, were prepared using a method we developed and adapted, consisting of a change in the titania precursor concentration. The synthesized nanostructures exhibited significant absorption in the UV-vis range. The TRPS technique was shown to be a very useful tool for the characterization of metal-metal oxide core-shell nanostructures.
\end{abstract}

\section{Introduction}

In recent years, core-shell nanostructures (CSNs) have become one of the most widely studied hybrid structures [1,2]. This is because the combination of two or more different materials into one structure of controlled size, geometry and morphology can lead to either improved or new properties not observed in the individual constituent materials. CSNs with a silica core and noble metal shell exhibiting tunable optical properties depending on the ratio of core radius and shell thickness are an excellent example of such structures $[3,4]$. The CSNs, with either a silica core or shell, have found many applications due to 
their useful properties, including surface enhanced spectroscopy or cancer therapy [4-11]. For many applications, however, the use of titanium dioxide in CSNs would be of much greater interest. Useful physicochemical properties of titanium dioxide in its crystalline forms, rutile and anatase, such as high refractive index and photocatalytic activity have led to its use in many fields. For example, $\mathrm{TiO}_{2}$ nanomaterials have been investigated for their use in photocatalysis [12-14], photocatalytic fuel generation [15], photovoltaics and sensors [16,17]. The CSNs with noble metal ( $\mathrm{Au}, \mathrm{Ag}$ ) nanoparticles (NPs) as a core and $\mathrm{TiO}_{2}$ shell, Au@ $\mathrm{TiO}_{2}$ and $\mathrm{Ag} @ \mathrm{TiO}_{2}$, have great potential for use in these applications $[18,19]$. Surface plasmon resonance properties of gold and silver NPs can increase the optical absorption of titania and extend its absorption band to the visible light region. Such CSNs could allow one of the most important limitations in broader use of titania to be overcome: the limitation of photocatalytic capability to UV light $(\lambda<400 \mathrm{~nm})$. In addition, they may serve as a precursor for plasmon-sensitized colloidal perovskites, which are materials of great interest for solar cell applications [20].

The limiting factor in the broader use of $\mathrm{Ag} @ \mathrm{TiO}_{2}$ and $\mathrm{Au} @ \mathrm{TiO}_{2}$ structures could be their rather difficult synthesis process $[21,22]$. The main problem in coating various particles (including metal colloids) with titania is the very fast hydrolysis rate of its most commonly used precursors, titanium alkoxides, which makes the coating process hard to control [21]. This is also the main reason for the low monodispersity of $\mathrm{TiO}_{2}$ particles prepared from titanium alkoxides using the sol-gel method [23]. The limitations in titania coating can be overcome by using the less common but more expensive $\mathrm{TiO}_{2}$ precursors, various solvents or their mixtures, various additives such as surfactants or salts, and special reaction conditions in order to slow down the reaction rate. These strategies have been employed in a few successful attempts at controlled synthesis of $\mathrm{Ag} @ \mathrm{TiO}_{2}$ and $\mathrm{Au} @ \mathrm{TiO}_{2}$ structures reported in recent years [21,24-49].
However, these titania coating methods were used in the synthesis of either $\mathrm{Ag} @ \mathrm{TiO}_{2}$ [24-36] or $\mathrm{Au} @ \mathrm{TiO}_{2}$ [37-49] nanostructures with only a few exceptions of more general methods [21]. Another difficulty in the coating process arises from the possibility of core particle agglomeration. Since metal nanoparticles are vulnerable to agglomeration, additional actions, such as the use of special conditions or additives, have to be undertaken to prevent it. In addition, the confirmation of the shell formation (in almost all reported cases) has been based only on electron microscopy (mainly TEM) images and UV-vis spectroscopy, with a few exceptions of the additional use of either static or dynamic light scattering (SLS or DLS) $[21,27]$.

Here, we report a general and simple approach to the synthesis of $\mathrm{Ag} @ \mathrm{TiO}_{2}$ and $\mathrm{Au} @ \mathrm{TiO}_{2} \mathrm{CSNs}$ (Scheme 1). The proposed method works well for both gold and silver NPs without any additional adjustments and without the need for special reaction conditions. It also allows control of the shell thickness in the range of 20-30 nm up to $100 \mathrm{~nm}$ simply by changing the titania precursor concentration. These as-prepared materials have significant absorption in the UV and visible range and therefore have high potential for applications in solar-light-driven photocatalysis and photovoltaics. In addition, we show for the first time the potential of the tunable resistive pulse sensing (TRPS) technique in the characterization of metal-oxide CSNs. TRPS, which in a relatively easy and fast way provides statistical information regarding the size and size distribution of the studied particles, can be a valuable tool in the characterization of various nanoparticles in addition to electron microscopy.

\section{Results and Discussion \\ Synthesis of $\mathrm{Ag} @ \mathrm{TiO}_{2}$ and $\mathrm{Au} @ \mathrm{TiO}_{2}$}

Our studies on the fabrication of CSNs with a noble metal core and titania shell were aimed at the development of a general and simple method which requires a minimal number of additives (or none at all) and allows control of the structural features of

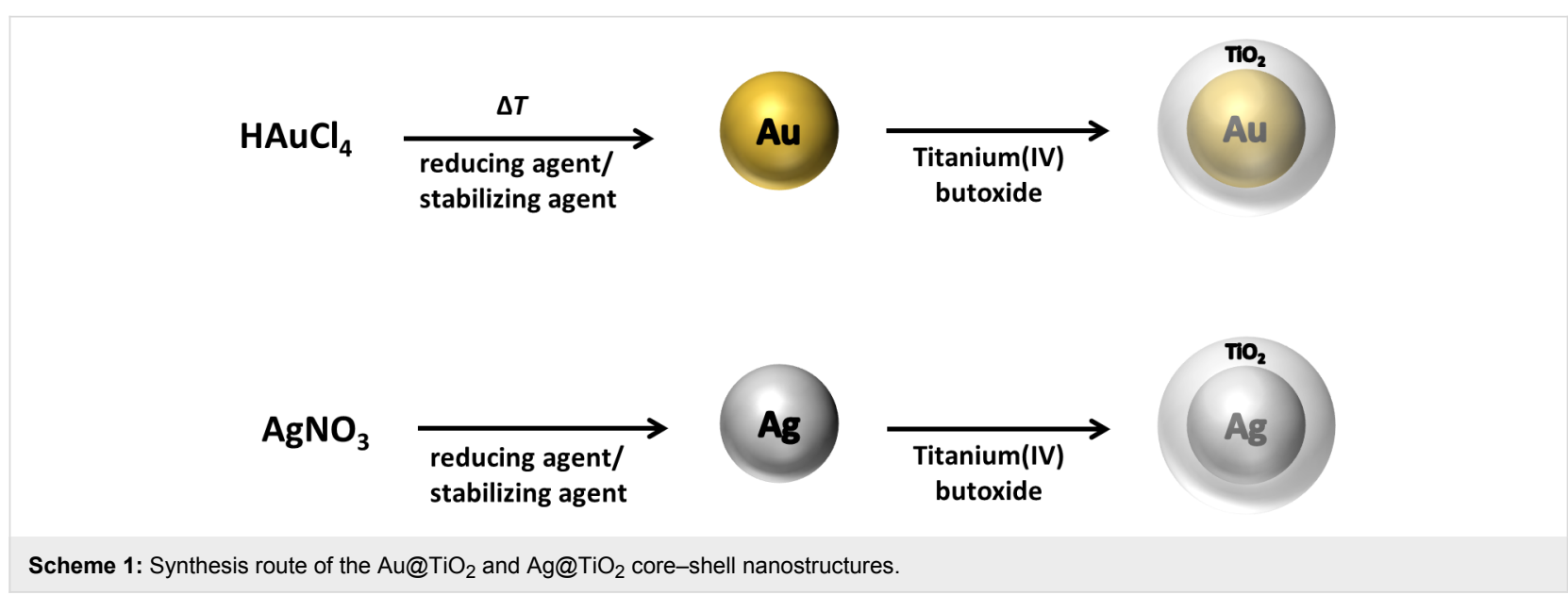


the CSNs in addition to synthesis in larger amounts. The $\mathrm{TiO}_{2}$ coating strategy used in the synthesis of $\mathrm{Ag} @ \mathrm{TiO}_{2}$ and $\mathrm{Au} @ \mathrm{TiO}_{2} \mathrm{CSNs}$ is outlined in Scheme 1. In the first step, we synthesized AuNPs using the Frens method and AgNPs by the reduction of silver nitrate with hydroxylamine hydrochloride $[50,51]$. In both cases, relatively monodisperse spherical or quasi-spherical metal NPs with a mean particle diameter of around $100 \mathrm{~nm}$ were obtained (Table 1, Figure 1 and Figure S1, Supporting Information File 1). Initially, we also used the Frens method to synthesize AgNPs. As a result, however, we obtained significant amounts of rod-like and triangular particles in addition to spherical particles. The titania coating method described here allowed coating of all AgNPs regardless of shape, but such CSNs were not very useful for further analysis from a statistical point of view and therefore were not presented in this article. In addition, we found that the methodology described here works very well for nanoparticles with diameters greater than $50 \mathrm{~nm}$. In cases of smaller nanoparticles, with diameters of $20 \mathrm{~nm}$ and less, we observed formation of the multi-core@shell particles, which are also very interesting due to the combined plasmonic effect of metallic cores.

In the case of AgNPs, the synthesized metal NPs were stabilized with citrate ions either during the synthesis or after, in order to prevent aggregation in the coating solution. Citrate stabilized AuNPs and AgNPs disperse well in the reaction mixture used, ethanol and acetonitrile, and do not undergo undesirable aggregation. In previously reported studies metal nanoparticles were usually synthesized and stabilized in a separate step from coating [27-33,35-49]. However, in some of the reported methods, both the synthesis of NPs and their coating occurred in one reaction batch [24-26,34]. The former approach allows synthesis and coating of particles of various shapes and sizes. In the latter approach, control over the shape and size of the synthesized particles is limited. The metal nanoparticles were stabilized before the coating step using various surfactants or stabilizing agents such as Lutensol ON50 [21], cetyltrimethylammonium bromide (CTAB) [27-30,40], anionic poly(sodium 4-styrenesulfonate) (PSS) [49], mercaptoundecanoic acid [38,39], 1-ethenylpyrrolidin-2-one (PVP) [33,41], or hydroxypropyl cellulose [45-47]. In addition, in some studies, an adhesion layer was formed on the metal NP surface in order to better control the $\mathrm{TiO}_{2}$ shell growth [48].

The coating step of the method described here, being a modification of the titania particle synthesis method described elsewhere [52,53], small volumes of the concentrated aqueous suspensions of synthesized NPs were transferred into a mixture of ethanol and acetonitrile. The hydrolysis reaction catalyst, methylamine, was then added to a suspension of NPs. The role of the amine catalysts is to transfer a proton from the water mol- ecule to the oxygen atoms in titanium alkoxide molecules. As a result, good leaving groups of alcohols are formed, which are then easily replaced by hydroxide anions. In the next step, titanium(IV) butoxide (TBT) solution in absolute ethanol was added dropwise. The first indication of the start of the coating process was observed shortly after precursor addition; however, the reaction was allowed to proceed for a few hours to ensure formation of the complete shell. The shell formation on metal NPs is accompanied by the unavoidable formation of free $\mathrm{TiO}_{2}$ particles, which together with residual chemicals, are removed by a few centrifugation/wash/redispersion cycles in ethanol.

The method described here for titania coating of metal NPs is simple and does not require special conditions. The reaction is carried out at room temperature without the need for an inert atmosphere. However, due to the sensitivity of titanium alkoxides to water, care should still be taken while handling the $\mathrm{TiO}_{2}$ precursor. This is one of the reasons why we used TBT in our method as a shell precursor instead of titanium(IV) isopropoxide or titanium(IV) ethoxide. We found that TBT is more stable and reacts slower than titania precursors with smaller alkyl groups. This finding is in agreement with previously reported results, indicating that hydrolysis and condensation rates of titanium alkoxides decrease when the alkyl group size increases due to the partial charge and steric effects $[54,55]$. In previously reported studies on titania coating, in order to achieve better control of the coating process, titanium alkoxides were converted to titanium glycolate before coating $[35,56]$ or coating was carried out using less common $\mathrm{TiO}_{2}$ precursors such as, titanium(IV) bis(ammonium lactato) dihydroxide [37] or titanium diisopropoxide bis(acetylacetonate) [45-47]. TBT also has an additional advantage: it is cheaper than other $\mathrm{TiO}_{2}$ precursors which could be an important factor when considering scaling up of the synthesis. Despite the relative stability of TBT, the use of anhydrous solvents was necessary in order to avoid premature hydrolysis of TBT in the ethanol solution, and also to avoid the uncontrolled introduction of water to the reaction mixture. Water, necessary for titania precursor hydrolysis, is introduced to the reaction mixture in a controlled way from two sources, NPs suspensions $(\approx 199 \mu \mathrm{L})$ and amine catalysts solutions $(\approx 24 \mu \mathrm{L}$ of water $)$, before addition of the shell precursor. The total volume of added water to the reaction mixture was kept constant, which allowed the control of thicknesses of the titania coating by only varying the TBT concentration in the final reaction mixture (Table S1, Supporting Information File 1).

\section{Morphology, size and shell thickness of $\mathrm{Ag} @ \mathrm{TiO}_{2}$ and $\mathrm{Au} @ \mathrm{TiO}_{2}$}

The characterization of the structural features, size and shell thickness of CSNs, such as those described in this article, is 
complicated. Traditionally, only electron microscopy techniques (TEM or SEM) and UV-vis spectroscopy have been used to prove that the coating was in fact achieved and to provide information regarding shell thickness [21,24-49,57]. A few exceptions concerning the additional use of SLS or DLS have also been reported [21,27]. However, any statistical data on the CSN size and shell thickness have been based only on the analysis of transmission electron microscopy images due to the high resolution of this technique. Recently, it has been demonstrated that of the various particle sizing techniques, two of them (differential centrifugal sedimentation (DCS) and tunable resistive pulse sensing (TRPS) $[58,59]$ ) are capable of achieving resolution similar to the TEM technique. Both techniques allow the analysis of many more particles than TEM, and thus better statistics are obtained in a simpler way, in shorter time and much more cheaply. The main drawback of these techniques is that they cannot provide information regarding the shape of particles and should therefore always be used together with either TEM or SEM. The DCS technique has already been employed to investigate some types of CSNs, but these studies were possible due to knowledge of the density values of both core and shell, which are necessary for the analysis [60-62]. For the same reason, the use of the DCS technique for the characterization of fabricated CSNs was not possible in our case due to the lack of the shell density value, necessary for the determination of particle diameter based on Stokes' Law. Regarding the CSNs studied, we found that the TRPS technique could be a very valuable addition to electron microscopy techniques in the characterization of CSNs. TRPS, based on the Coulter principle, monitors changes in ionic current as individual particles pass through an elastomeric membrane containing a single pore of precisely controlled size. Because TRPS allows measurement particle-by-particle, any central value or spread statistic based on hundreds or thousands of individual measurements can be calculated and transformed for direct comparison with ensemble average data. In contrast to electron microscopy, TRPS does not entail difficult sample preparation and experimental artefacts, and is significantly cheaper. More importantly, TRPS measurements are independent of particle density and optical properties such as particle labelling or refractive index [63-65]. In fact, it is the only technique among more common and cheaper ones which allows such valuable statistical data to be obtained in the case of CSNs.

SEM images and TRPS size histograms of synthesized $\mathrm{Au} @ \mathrm{TiO}_{2}$ and $\mathrm{Ag} @ \mathrm{TiO}_{2} \mathrm{CSNs}$ are presented in Figure 1 and Figure 2, respectively. TRPS size histograms of NPs are presented in Figure S1, Supporting Information File 1. The detailed statistical data regarding size and shell thicknesses of synthesized nanostructures, mean $\left(D_{\mathrm{P}}\right.$ mean $)$, mode $\left(D_{\mathrm{P}}\right.$ mode), median $\left(D_{\mathrm{P}} 50\right)$, maximum $\left(D_{\mathrm{P}} \max \right)$ and minimum $\left(D_{\mathrm{P}} \min \right)$ values of core particles and CSNs diameters as well as the shell thicknesses $(d)$ calculated based on these values are provided in Table 1. Authors very often do not provide sufficient information regarding size distribution, giving only mean size with standard deviation. This suggests that size distribution means Gaussian distribution, which in many cases does not reflect real size distribution. Therefore, the inclusion of other size parameters in order to describe the width of the distribution such as values of mean, median and mode diameters is recommended. The mean diameter is a calculated value similar to the concept of average and provides information regarding the average size of all measured particles. Median diameter value is defined as the value where half of the particle population has a smaller size, and half has a larger size. The mode value represents the particle size (or size range) most commonly found in the distribution. For symmetric distributions such as the one shown in

\begin{tabular}{|c|c|c|c|c|c|c|c|c|c|c|}
\hline Samples & $\begin{array}{l}D_{\mathrm{P}} \text { mean } \\
{[\mathrm{nm}]}\end{array}$ & $\begin{array}{c}D_{\mathrm{P}} \text { mode } \\
{[\mathrm{nm}]}\end{array}$ & $\begin{array}{c}D_{\mathrm{P}} 50 \\
{[\mathrm{~nm}]}\end{array}$ & $\begin{array}{c}D_{\mathrm{P}} \min \\
{[\mathrm{nm}]}\end{array}$ & $\begin{array}{c}D_{\mathrm{P}} \max \\
{[\mathrm{nm}]}\end{array}$ & $\begin{array}{c}d \text { mean } \\
{[\mathrm{nm}]^{\mathrm{b}}}\end{array}$ & $\begin{array}{c}d \text { mode } \\
{\left[\mathrm{nm}^{\mathrm{C}}\right]^{\mathrm{c}}}\end{array}$ & $\begin{array}{c}d D_{\mathrm{p}} 50 \\
{[\mathrm{~nm}]^{\mathrm{d}}}\end{array}$ & $\begin{array}{l}d \min \\
{[\mathrm{nm}]^{\mathrm{e}}}\end{array}$ & $\begin{array}{l}d \max \\
{[\mathrm{nm}]^{f}}\end{array}$ \\
\hline Au NPs & 101 & 98 & 99 & 77 & 143 & - & - & - & - & - \\
\hline$A$ & 192 & 165 & 189 & 121 & 253 & 45 & 33 & 45 & 22 & 55 \\
\hline B & 205 & 185 & 193 & 126 & 313 & 52 & 43 & 47 & 25 & 85 \\
\hline C & 244 & 195 & 227 & 152 & 384 & 71 & 48 & 64 & 38 & 121 \\
\hline $\mathrm{D}$ & 300 & 245 & 284 & 202 & 401 & 99 & 73 & 93 & 63 & 129 \\
\hline $\mathrm{Ag} N \mathrm{NP}$ & 116 & 111 & 113 & 82 & 160 & - & - & - & - & - \\
\hline$E$ & 188 & 165 & 180 & 141 & 273 & 36 & 27 & 34 & 30 & 57 \\
\hline $\mathrm{F}$ & 204 & 204 & 200 & 142 & 303 & 44 & 46 & 44 & 30 & 72 \\
\hline G & 243 & 215 & 234 & 162 & 341 & 63 & 52 & 61 & 40 & 91 \\
\hline $\mathrm{H}$ & 261 & 225 & 249 & 170 & 343 & 72 & 57 & 68 & 44 & 92 \\
\hline
\end{tabular}

${ }^{\mathrm{a}} D_{\mathrm{P}}$ - particle diameter; $d$-shell thickness. The shell thickness obtained based on the values of ${ }^{\mathrm{b}}$ mean $D_{\mathrm{P}},{ }^{\mathrm{c}}$ mode $D_{\mathrm{P}},{ }^{\mathrm{d}} D_{\mathrm{P}} 50$ (median), ${ }^{\mathrm{e}}$ minimum $D_{\mathrm{P}}\left(D_{\mathrm{P}}\right.$ min $)$ and ${ }^{\mathrm{f}}$ maximum $D_{\mathrm{P}}\left(D_{\mathrm{P}} \max \right)$. 
Supporting Information File 1, Figure S1 and Table 1 for AuNPs, all values, mean, median and mode, are equivalent. However, the situation changes upon titania coating. In the case of both $\mathrm{Au} @ \mathrm{TiO}_{2}$ and $\mathrm{Ag} @ \mathrm{TiO}_{2} \mathrm{CSNs}$, TRPS size histograms indicate that with increasing shell thickness the non-uniformity of the size distribution with respect to metallic cores (Figure 1,
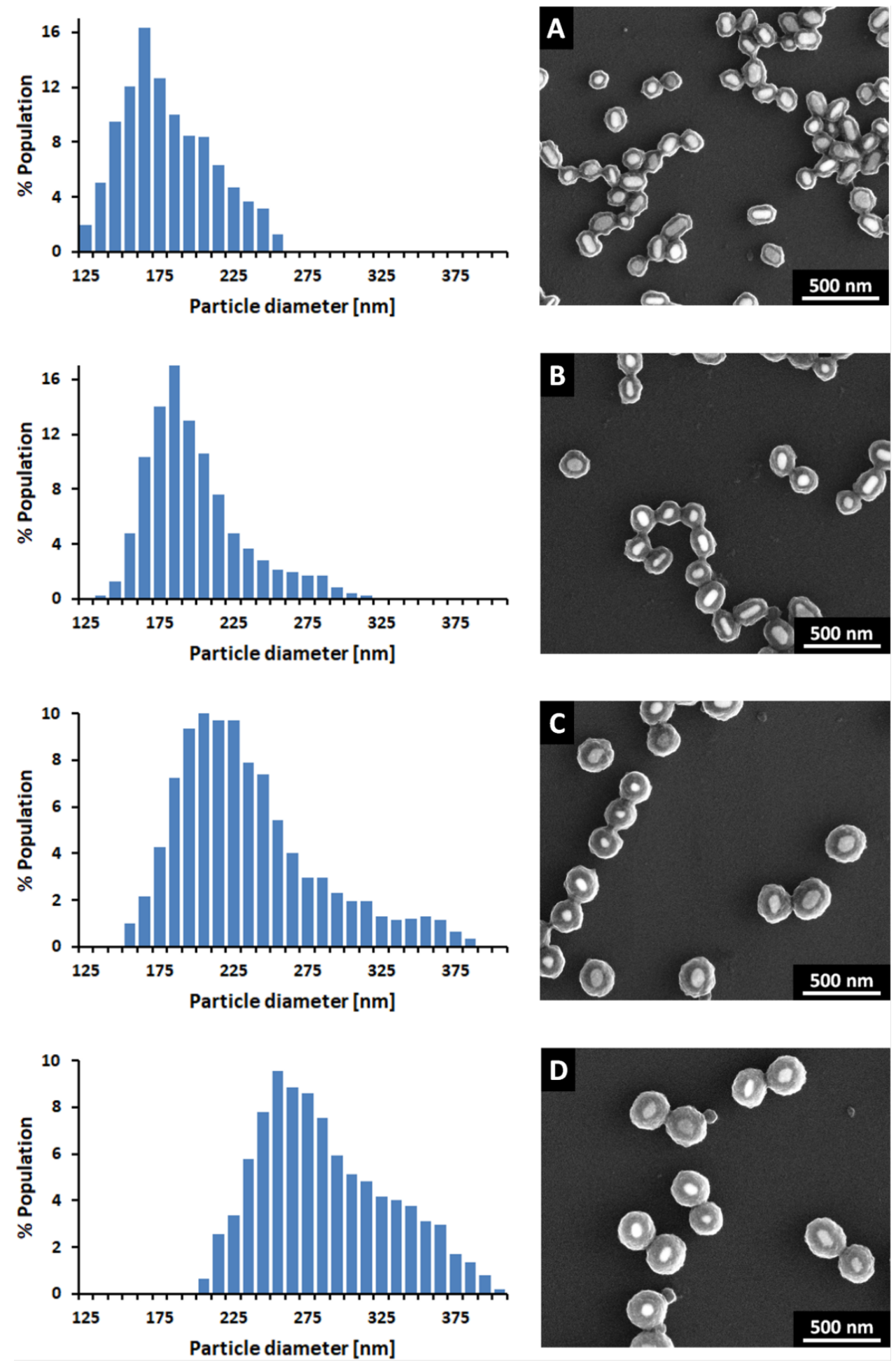

Figure 1: SEM images and TRPS size histograms of $A u @ T i O_{2}$ (Samples A-D) structures with various titania shell thicknesses (see Table 1). 

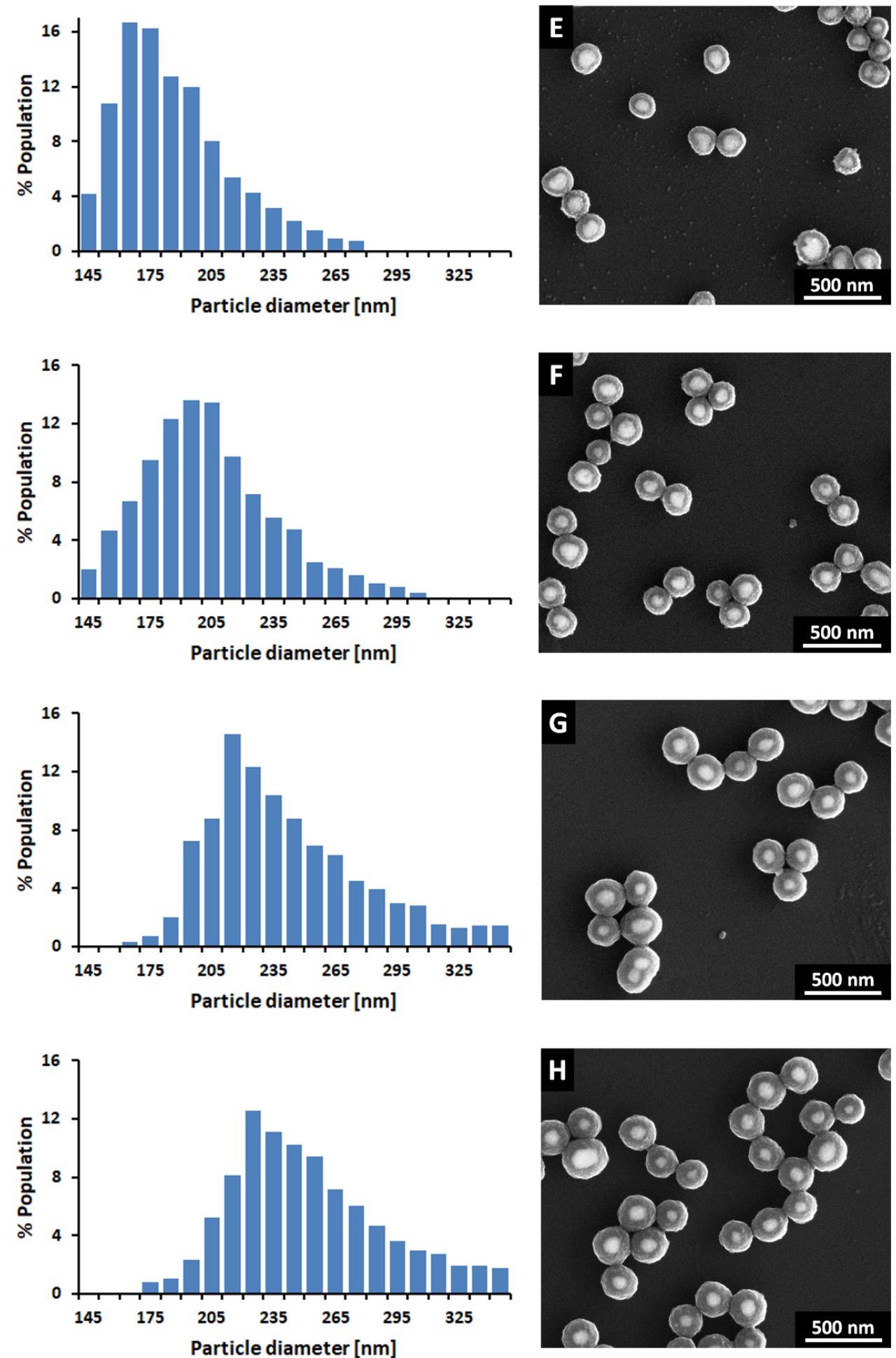

Figure 2: SEM images and TRPS size histograms of $\mathrm{Ag@TiO}$ (Samples $\mathrm{E}-\mathrm{H})$ structures with various titania shell thicknesses (see Table 1).

Figure 2 and Supporting Information File 1, Figure S1) also increases. This finding was not easily observed based on the analysis of SEM images with a small number of particles. In order to obtain good statistical data, a SEM analysis would require a time-consuming investigation of the many SEM images with a larger number of CSNs. 
The results obtained using SEM and TRPS, as shown in Figure 1, Figure 2, Table 1 and Supporting Information File 1, Table S1, clearly show that increasing the titania precursor concentration in the final reaction mixture results in thicker titania shells. In the case of AgNPs with $D_{\mathrm{P}} 50=113 \mathrm{~nm}$ under the applied reaction conditions (Supporting Information File 1, Table S1), the titania shell thickness changes from $34 \mathrm{~nm}$ to $68 \mathrm{~nm}$ based on the $D_{\mathrm{P}} 50$ values of the diameters. A similar range of titania shell thickness values is obtained based on the $D_{\mathrm{P}}$ mean values of the diameters. In $D_{\mathrm{P}}$ mode values, all but one value of the shell thickness is smaller than the corresponding $d$ values calculated for $D_{\mathrm{P}} 50$ and $D_{\mathrm{P}}$ mean. In the case of AuNPs with $D_{\mathrm{P}} 50=99 \mathrm{~nm}$ under the applied reaction conditions (Supporting Information File 1, Table S1), the titania shell thickness changes from $45 \mathrm{~nm}$ to $93 \mathrm{~nm}$ based on the $D_{\mathrm{P}} 50$ values of the diameters. A similar range of the titania shell thickness values is obtained based on the $D_{\mathrm{P}}$ mean values of the diameters. In the case of the $D_{\mathrm{P}}$ mode, all values of shell thickness are smaller than the corresponding values calculated for $D_{\mathrm{P}} 50$ and $D_{\mathrm{P}}$ mean.

Under certain assumptions, analysis of the $d$ values calculated based on the $D_{\mathrm{P}} \max$ and $D_{\mathrm{P}}$ min (the largest and the smallest particles in the samples) can provide information about the theoretical range of the titania shell thickness values for each series of CSNs, Samples A-H. The analysis of the SEM images of the CSNs investigated revealed that for the AgNPs and AuNPs of similar sizes, the shell thicknesses seem to be very uniform. We have not observed CSNs with titania shell thicknesses which were much larger or smaller compared to shell thicknesses of other CSNs. We are aware, however, that a small number of CSNs in the population may have much thinner or much thicker shells. Based on these findings we have assumed in our calculations that metal NPs with $D_{\mathrm{P}}$ min yield CSNs with $D_{\mathrm{P}}$ min and metal NPs with $D_{\mathrm{P}}$ max yield CSNs with $D_{\mathrm{P}}$ max. Taking into consideration the above assumptions, the thinnest obtained titania shell was about $22 \mathrm{~nm}$ for AuNPs and about $30 \mathrm{~nm}$ for AgNPs. Interestingly, the value of $d$ min increases more slowly for AgNPs than for AuNPs. A similar trend is observed for $d$ max. The $d$ max under the applied reaction conditions reaches almost $130 \mathrm{~nm}$ for AuNPs, while only $90 \mathrm{~nm}$ for AgNPs.

\section{Optical properties of $\mathrm{Ag} @ \mathrm{TiO}_{2}$ and $\mathrm{Au} @ \mathrm{TiO}_{2}$}

The UV-vis spectra of metal NPs and CSNs fabricated from them are shown in Figure 3. In order to better visualize the optical properties of the fabricated CSNs, images of their water suspensions and powders after drying are shown in Supporting Information File 1, Figure S2. In the case of the CSNs, we observed that upon coating of metal NPs with titania, the optical properties change significantly compared to the optical proper- ties of the core and the shell material alone (Figure 3 and Supporting Information File 1, Figure S3).
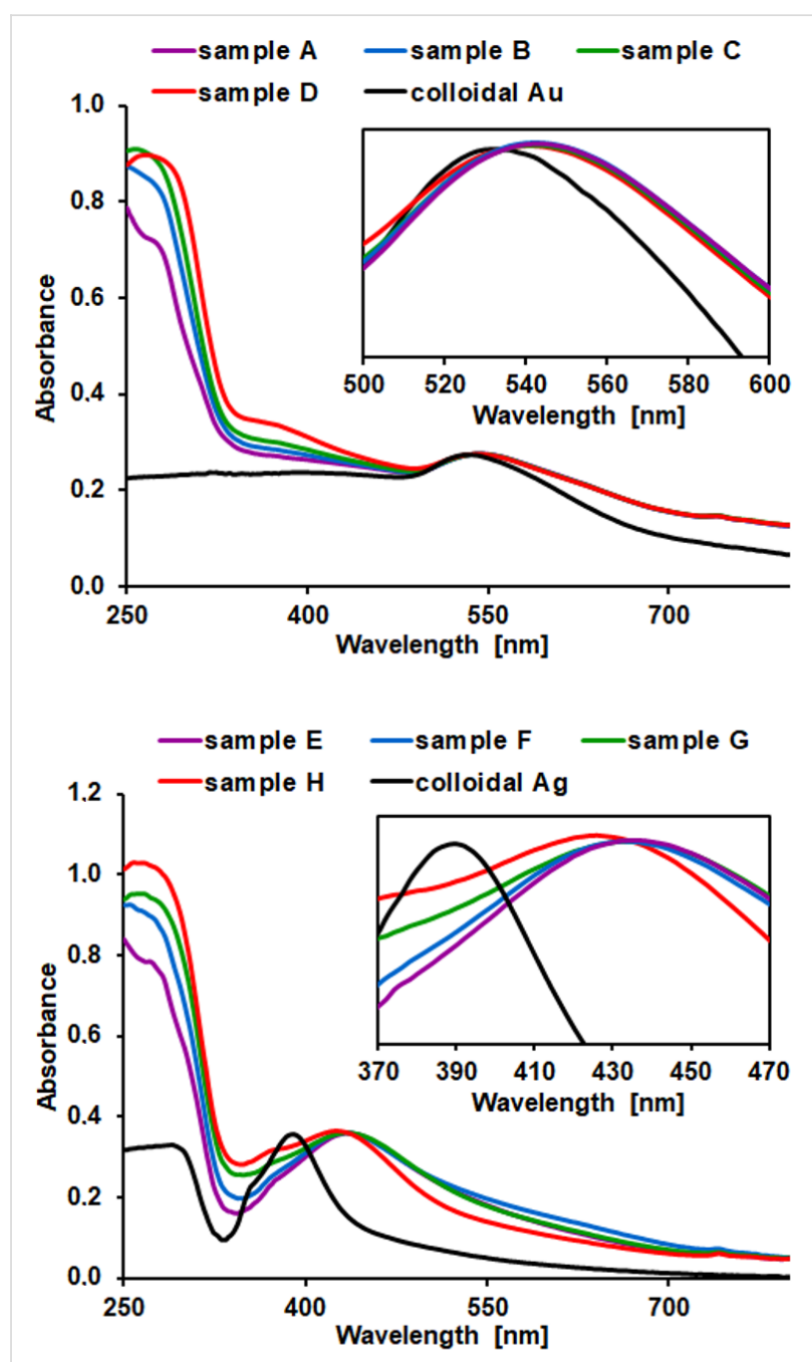

Figure 3: Normalized UV-vis spectra of noble metal colloids and noble metal@ $\mathrm{TiO}_{2}$ core-shell nanostructures for Au (top) and Ag (down). All spectra were normalized to the peaks relative to the surface plasmon resonances of CSNs.

The fabricated CSNs absorb light in the whole UV-vis range and therefore their optical properties compared to $\mathrm{TiO}_{2}$ particles are considered to be improved (Supporting Information File 1, Figure S3). In addition, when comparing the optical properties of metal NPs and the CSNs, red shifts of the maxima of absorption in CSNs $\left(\lambda_{\max }=390 \mathrm{~nm}\right.$ vs $\lambda_{\max }=424 \mathrm{~nm}$ for AgNPs and $\lambda_{\max }=528 \mathrm{~nm}$ vs $\lambda_{\max }=540 \mathrm{~nm}$ for AuNPs) were observed (Figure 3 ). This effect is related to the fact that the spectral location of plasmon resonance of single noble metal nanoparticles is dependent on the refractive index $(n)$ of the surrounding medium $[28,56]$. Coating metal NPs with $\mathrm{TiO}_{2}(n \approx$ 2.2-2.6) leads to an overall increase in the refractive index of their local dielectric environment, and as a result, to the red 
shift of the plasmon resonance. In the case of both $\mathrm{Ag} @ \mathrm{TiO}_{2}$ and $\mathrm{Au} @ \mathrm{TiO}_{2}$, the changes in the shell thickness do not significantly influence the position of the plasmon resonance and overall extinction in the UV-vis range. However, an additional increase in the red shift of maxima of absorption is expected upon transformation of the amorphous titania shell to crystalline form.

Improved optical properties of titania-based hybrid nanostructures make them interesting materials for application in dyesensitized solar cells (DSSCs) and photocatalysis. In fact, it has been shown that plasmonic nanostructures can enhance the efficiency of DSSCs by four possible mechanisms [66]. The farfield coupling of scattered light and the near-field coupling of electromagnetic fields increased the efficiency of light interaction with sensitizers (dyes). On the other hand, plasmon resonance energy transfer (PRET) and "hot" electron transfer led to an increased $\mathrm{e}^{-} / \mathrm{h}^{+}$pair generation and amplified number of carriers available for photocurrent generation. An increased number of $\mathrm{e}^{-} / \mathrm{h}^{+}$pairs should also result in improved photocatalytic properties of titania-based plasmonic nanostructures.

\section{Conclusion}

In this paper, we have shown that by using a general and simple approach it is possible to synthesize $\mathrm{Ag} @ \mathrm{TiO}_{2}$ and $\mathrm{Au} @ \mathrm{TiO}_{2}$ CSNs with shell thickness of $\approx 40-70 \mathrm{~nm}$ and $90 \mathrm{~nm}$, for AgNPs and AuNPs, respectively (based on the $D_{\mathrm{P}} 50$ values). In the titania coating method developed, we used titanium(IV) butoxide, the least expensive of the organic titanium alkoxides, and used it under mild reaction conditions at room temperature and with no inert atmosphere or special glassware. The method was applicable to both gold and silver particles under exactly the same conditions and this allowed us to obtain relatively large amounts of the CSNs in a single batch. In previously reported studies, titania coating of noble metal nanoparticles was achieved by using various, more or less complicated approaches. These approaches included the use of the less common and thus more expensive titania precursors, which are laborious in preparation. The other approaches included the use of various solvents or their mixtures, various additives such as surfactants or salts, special reaction conditions, and multistep processes. In addition, these strategies were employed in the synthesis of either $\mathrm{Ag} @ \mathrm{TiO}_{2}$ or $\mathrm{Au} @ \mathrm{TiO}_{2}$ structures with some exceptions, including more general methods. Moreover, in all previous studies, information regarding the shell thickness was obtained mainly from the analysis of electron microscope images, which have some limitations in terms of the statistical analysis. In our studies, we applied the TRPS technique to characterize the metal-metal oxide core-shell nanostructures for the first time. This technique allowed us, in a very convenient and fast way, to analyze hundreds of CSNs per sample and to obtain very detailed statistical data regarding their size and size distribution. However, TRPS does not provide information about the shape of the investigated particles and in their analysis always has to be used as a complementary tool to electron microscopy techniques. Fabricated core-shell nanostructures have significant extinction in the UV and visible range and therefore should be of great interest for applications in solar-light-driven photocatalysis and photovoltaics. In the future, studies will be carried out to further optimize reaction conditions toward coating nanoparticles with diameter of less than $20 \mathrm{~nm}$ and to obtain thinner shells. In addition, studies will be dedicated to converting the titania shell of the synthesized CSNs to either crystalline titania (anatase, rutile or their mix) or perovskites and to testing the performance of such systems in various applications in comparison to regular titania or perovskite particles.

\section{Experimental \\ Chemicals}

All chemicals, including sodium citrate dihydrate (>99\%), hydroxylamine hydrochloride $(>99 \%)$, gold(III) chloride hydrate $(99.99 \%)$ and titanium(IV) butoxide $(>97 \%)$ were purchased from Sigma-Aldrich. Methylamine (40\% w/w aq. soln.) and silver nitrate $(99.9 \%)$ were purchased from Alfa Aesar. Ethanol (99.8\%) and acetonitrile (99.5\%) were purchased from Avantor Performance Materials Poland. Nitric acid (65\% w/w aq. soln.), hydrofluoric acid $(40 \% \mathrm{w} / \mathrm{w}$ aq. soln.) and sodium hydroxide $(>99 \%)$ were purchased from Chempur. All purchased chemicals were used as received without further purification. Ultrapure deionized (DI) water $\left(18.2 \mathrm{M} \Omega \cdot \mathrm{cm}\right.$ at $25^{\circ} \mathrm{C}$, Hydrolab, Poland) was used throughout the experiments. All glassware was treated with titania etching solution $\left(\mathrm{HF} / \mathrm{HNO}_{3} /\right.$ $\mathrm{H}_{2} \mathrm{O}=1: 4: 15 \mathrm{v} / \mathrm{v} / \mathrm{v}$ ) for $5 \mathrm{~min}$ and rinsed with DI water and acetone several times.

\section{Gold colloids}

Gold colloids were prepared using the Frens method. $100 \mathrm{~mL}$ of $0.01 \%(\mathrm{w} / \mathrm{w})$ aqueous $\mathrm{HAuCl}_{4}$ solution were heated to boiling point and $0.6 \mathrm{~mL}$ of $1 \%(\mathrm{w} / \mathrm{w})$ of sodium citrate solution were added. In ca. 2 min the boiling solution turned blue (nucleation) and after approximately 5 min the color suddenly changed into red, indicating the formation of spherical gold nanoparticles. After cooling down to room temperature the reaction mixture was centrifuged and $3 \mathrm{~mL}$ of concentrated colloidal gold solution were collected from the bottom of the tube.

\section{Silver colloids}

$90 \mathrm{~mL}$ of aqueous solution of silver nitrate $(1.1 \mathrm{mM})$ were stirred at room temperature. $10 \mathrm{~mL}$ of solution containing hydroxylamine hydrochloride $(25 \mathrm{mM})$ and sodium hydroxide $(0.1 \mathrm{w} / \mathrm{w} \%)$ were added. The reaction was completed within a few seconds, which was indicated by a change of solution color 
to milky yellow. In order to stabilize the silver colloids, $5 \mathrm{~mL}$ of aqueous sodium citrate solution $(1 \mathrm{w} / \mathrm{w} \%)$ were added to the final mixture. The reaction mixture was then centrifuged and $3 \mathrm{~mL}$ of concentrated colloidal silver solution were collected from the bottom of the tube.

\section{Metal@ $\mathrm{TiO}_{2}$ core-shell nanostructures}

Metal NPs-titania CSNs were prepared by hydrolysis and polycondensation reaction of titanium(IV) butoxide (TBT). $40 \mathrm{~mL}$ of a mixture of ethanol and acetonitrile $(50 / 50 \mathrm{v} / \mathrm{v} \%)$ were stirred at room temperature. $200 \mu \mathrm{L}$ of the metal nanoparticle concentrated solution $(\approx 199 \mu \mathrm{L}$ of water $)$ and $45 \mu \mathrm{L}$ of the methylamine solution $(24.2 \mu \mathrm{L}$ of water) were added to this mixture. Next, $8 \mathrm{~mL}$ of the TBT solution in ethanol were added dropwise (concentrations of TBT in final mixtures are given in Supporting Information File 1, Table S1). In about 15 min the stirred solution turned milky red or milky yellow for gold or silver nanoparticles, respectively. The stirring was kept up for $12 \mathrm{~h}$. After this time, the synthesized CSNs were centrifuged and washed several times with ethanol.

\section{Tunable resistive pulse sensing (TRPS) measurements}

Analogous to the description in [64], TRPS size distribution measurements were carried out using a qNano instrument (Izon Science) with tunable nanopore membranes NP100 (50-200 nm particles size range) for metal colloid measurements and NP150 (100-400 nm particle size range) for the CSNs measurements. The upper and lower cell chambers were filled with an electrolyte (PBS buffer). The arms of the cruciform mount were initially mechanically stretched in the $X-Y$ axis to $\approx 47 \mathrm{~mm}$ and later the $\mathrm{X}-\mathrm{Y}$ deformation was adjusted for resolution optimization. For all measurements, $40 \mu \mathrm{L}$ of a suspension of measured particles in the PBS buffer was added to the upper fluid cell compartment, while the lower cell contained pure PBS buffer solution. Experimental conditions, including degree of membrane stretch, applied voltage and pressure, were tuned to optimize the resolution for measurement of each sample. The measurements were conducted for at least 500 particles for each sample. The calibration measurement was carried out after measurement of each sample (with the same conditions) using carboxylated polystyrene nanoparticles (100 nm or $200 \mathrm{~nm}$ ) supplied by the manufacturer. The statistical data for the particle size distribution, including mean particle diameter, mode particle diameter, max and min particle diameter $\left(D_{\mathrm{P}} 10, D_{\mathrm{P}} 50\right.$ and $\left.D_{\mathrm{P}} 90\right)$ were calculated using the software provided with the instrument.

\section{UV-vis measurements}

The UV-vis extinction spectra were measured at room temperature using a Lambda 900 UV-vis-NIR spectrophotometer
(Perkin Elmer) in the 250-800 $\mathrm{nm}$ spectral range. Suspensions of the synthesized nanostructures were measured in a $1 \mathrm{~cm}$ optical path quartz cuvette placed inside the integration sphere.

\section{SEM measurements}

The morphology of $\mathrm{Ag} @ \mathrm{TiO}_{2}$ and $\mathrm{Au} @ \mathrm{TiO}_{2}$ structures was characterized based on the images obtained using a Quanta 3D FEG dual beam scanning electron microscope. The samples for SEM were prepared by drop-casting suspensions of the core-shell nanostructures on a silicon wafer and drying in air.

\section{Supporting Information}

\author{
Supporting Information File 1 \\ Additional experimental data. \\ TRPS size histograms, images, UV-vis spectra and TBT \\ concentration information. \\ [http://www.beilstein-journals.org/bjnano/content/ \\ supplementary/2190-4286-8-208-S1.pdf]
}

\section{Acknowledgements}

This work was supported by the Polish National Science Centre [grant no. 2011/03/D/ST5/06038]. The TRPS instrument used in this research was obtained with funds from the Polish Ministry of Science and Higher Education grant for investment in large research infrastructure [grant no. 6434/IA/SP/2015]. This work was performed in the context of the European COST Action MP1302 Nanospectroscopy.

\section{References}

1. Chaudhuri, R. G.; Paria, S. Chem. Rev. 2012, 112, 2373-2433. doi:10.1021/cr100449n

2. Gawande, M. B.; Goswami, A.; Asefa, T.; Guo, H.; Biradar, A. V.; Peng, D.-L.; Zboril, R.; Varma, R. S. Chem. Soc. Rev. 2015, 44, 7540-7590. doi:10.1039/c5cs00343a

3. Oldenburg, S. J.; Averitt, R. D.; Westcott, S. L.; Halas, N. J. Chem. Phys. Lett. 1998, 288, 243-247. doi:10.1016/S0009-2614(98)00277-2

4. Jiang, R.; Li, B.; Fang, C.; Wang, J. Adv. Mater. 2014, 26, 5274-5309. doi:10.1002/adma.201400203

5. Li, J. F.; Huang, Y. F.; Ding, Y.; Yang, Z. L.; Li, S. B.; Zhou, X. S.; Fan, F. R.; Zhang, W.; Zhou, Z. Y.; Wu, D. Y.; Ren, B.; Wang, Z. L.; Tian, Z. Q. Nature 2010, 464, 392-395. doi:10.1038/nature08907

6. Sanz-Ortiz, M. N.; Sentosun, K.; Bals, S.; Liz-Marzán, L. M. ACS Nano 2015, 9, 10489-10497. doi:10.1021/acsnano.5b04744

7. Rodríguez-Fernández, D.; Langer, J.; Henriksen-Lacey, M.; Liz-Marzán, L. M. Chem. Mater. 2015, 27, 2540-2545. doi:10.1021/acs.chemmater.5b00128

8. Bardhan, R.; Grady, N. K.; Halas, N. J. Small 2008, 4, 1716-1722. doi:10.1002/smll.200800405

9. Loo, C.; Lin, A.; Hirsch, L.; Lee, M.-H.; Barton, J.; Halas, N.; West, J.; Drezek, R. Technol. Cancer Res. Treat. 2004, 3, 33-40. doi:10.1177/153303460400300104 
10. Bardhan, R.; Lal, S.; Joshi, A.; Halas, N. J. Acc. Chem. Res. 2011, 44, 936-946. doi:10.1021/ar200023x

11. Jankiewicz, B. J.; Jamioła, D.; Choma, J.; Jaroniec, M. Adv. Colloid Interface Sci. 2012, 170, 28-47. doi:10.1016/j.cis.2011.11.002

12. Chen, X.; Mao, S. S. Chem. Rev. 2007, 107, 2891-2959. doi:10.1021/cr0500535

13. Fujishima, A.; Zhang, X.; Tryk, D. A. Surf. Sci. Rep. 2008, 63, 515-582. doi:10.1016/j.surfrep.2008.10.001

14. Pelaez, M.; Nolan, N. T.; Pillai, S. C.; Seery, M. K.; Falaras, P.; Kontos, A. G.; Dunlop, P. S. M.; Hamilton, J. W. J.; Byrne, J. A.; O'Shea, K.; Entezari, M. H.; Dionysiou, D. D. Appl. Catal., B 2012, 125, 331-349. doi:10.1016/j.apcatb.2012.05.036

15. Ma, Y.; Wang, X.; Jia, Y.; Chen, X.; Han, H.; Li, C. Chem. Rev. 2014, 114, 9987-10043. doi:10.1021/cr500008u

16. Bai, Y.; Mora-Seró, I.; De Angelis, F.; Bisquert, J.; Wang, P. Chem. Rev. 2014, 114, 10095-10130. doi:10.1021/cr400606n

17. Bai, J.; Zhou, B. Chem. Rev. 2014, 114, 10131-10176. doi:10.1021/cr400625j

18. Dahl, M.; Liu, Y.; Yin, Y. Chem. Rev. 2014, 114, 9853-9889. doi:10.1021/cr400634p

19. Sang, L.; Zhao, Y.; Burda, C. Chem. Rev. 2014, 114, 9283-9318. doi:10.1021/cr400629p

20. Demirörs, A. F.; Imhof, A. Chem. Mater. 2009, 21, 3002-3007. doi:10.1021/cm900693r

21. Demirörs, A. F.; van Blaaderen, A.; Imhof, A. Langmuir 2010, 26 , 9297-9303. doi:10.1021/la100188w

22. Seh, Z. W.; Liu, S.; Han, M.-Y. Chem. - Asian J. 2012, 7, 2174-2184. doi:10.1002/asia.201200265

23. Jeong, U.; Wang, Y.; Ibisate, M.; Xia, Y. Adv. Funct. Mater. 2005, 15, 1907-1921. doi:10.1002/adfm.200500472

24. Pastoriza-Santos, I.; Koktysh, D. S.; Mamedov, A. A.; Giersig, M.; Kotov, N. A.; Liz-Marzán, L. M. Langmuir 2000, 16, 2731-2735. doi:10.1021/la991212g

25. Hirakawa, T.; Kamat, P. V. J. Am. Chem. Soc. 2005, 127, 3928-3934. doi:10.1021/ja042925a

26. Zhang, D.; Song, X.; Zhang, R.; Zhang, M.; Liu, F. Eur. J. Inorg. Chem. 2005, 1643-1648. doi:10.1002/ejic.200400811

27. Sakai, H.; Kanda, T.; Shibata, H.; Ohkubo, T.; Abe, M. J. Am. Chem. Soc. 2006, 128, 4944-4945. doi:10.1021/ja058083c

28. Wang, W.; Zhang, J.; Chen, F.; He, D.; Anpo, M. J. Colloid Interface Sci. 2008, 323, 182-186. doi:10.1016/j.jcis.2008.03.043

29. Chuang, H.-Y.; Chen, D.-H. Nanotechnology 2009, 20, 105704. doi:10.1088/0957-4484/20/10/105704

30. Yue, L.; Wang, Q.; Zhang, X.; Wang, Z.; Xia, W.; Dong, Y. Bull. Korean Chem. Soc. 2011, 32, 2607-2610. doi:10.5012/bkcs.2011.32.8.2607

31. Wang, P.; Wang, D.; Xie, T.; Li, H.; Yang, M.; Wei, X. Mater. Chem. Phys. 2008, 109, 181-183. doi:10.1016/j.matchemphys.2007.11.019

32. Vaidya, S.; Patra, A.; Ganguli, A. K. J. Nanopart. Res. 2010, 12, 1033-1044. doi:10.1007/s11051-009-9663-5

33. Qi, J.; Dang, X.; Hammond, P. T.; Belcher, A. M. ACS Nano 2011, 5, 7108-7116. doi:10.1021/nn201808g

34. Al-Mamun, M. A.; Kusumoto, Y.; Zannat, T.; Islam, M. S. Appl. Catal., A 2011, 398, 134-142. doi:10.1016/j.apcata.2011.03.027

35. Yang, X. H.; Fu, H. T.; Wong, K.; Jiang, X. C.; Yu, A. B. Nanotechnology 2013, 24, 415601. doi:10.1088/0957-4484/24/41/415601
36. Kumbhar, A.; Chumanov, G. J. Nanosci. Nanotechnol. 2004, 4, 299-303. doi:10.1166/jnn.2004.032

37. Mayya, K. S.; Gittins, D. I.; Caruso, F. Chem. Mater. 2001, 13, 3833-3836. doi:10.1021/cm011128y

38. Yu, Y.; Mulvaney, P. Korean J. Chem. Eng. 2003, 20, 1176-1182. doi:10.1007/BF02706958

39. Kwon, H.-W.; Lim, Y.-M.; Tripathy, S. K.; Kim, B.-G.; Lee, M.-S.; Yu, Y.-T. Jpn. J. Appl. Phys., Part 1 2007, 46, 2567-2570. doi:10.1143/JJAP.46.2567

40. Kanda, T.; Komata, K.; Torigoe, K.; Endo, T.; Sakai, K.; Abe, M.; Sakai, H. J. Oleo Sci. 2014, 63, 507-513. doi:10.5650/jos.ess 13203

41. Goebl, J.; Joo, J. B.; Dahl, M.; Yin, Y. Catal. Today 2014, 225, 90-95. doi:10.1016/j.cattod.2013.09.011

42. Li, J.; Zeng, H. C. Angew. Chem., Int. Ed. 2005, 44, 4342-4345. doi:10.1002/anie.200500394

43. Zhang, N.; Liu, S.; Fu, X.; Xu, Y.-J. J. Phys. Chem. C 2011, 115, 9136-9145. doi:10.1021/jp2009989

44. Du, J.; Qi, J.; Wang, D.; Tang, Z. Energy Environ. Sci. 2012, 5, 6914-6918. doi:10.1039/c2ee21264a

45. Seh, Z. W.; Liu, S.; Zhang, S.-Y.; Bharathi, M. S.; Ramanarayan, H.; Low, M.; Shah, K. W.; Zhang, Y.-W.; Han, M.-Y. Angew. Chem., Int. Ed. 2011, 50, 10140-10143. doi:10.1002/anie.201104943

46. Seh, Z. W.; Liu, S.; Zhang, S. Y.; Shah, K. W.; Han, M.-Y. Chem. Commun. 2011, 47, 6689-6691. doi:10.1039/c1cc11729g

47. Seh, Z. W.; Liu, S.; Low, M.; Zhang, S.-Y.; Liu, Z.; Mlayah, A.; Han, M.-Y. Adv. Mater. 2012, 24, 2310-2314. doi:10.1002/adma.201104241

48. Liu, W.-L.; Lin, F.-C.; Yang, Y.-C.; Huang, C.-H.; Gwo, S.; Huang, M. H.; Huang, J.-S. Nanoscale 2013, 5, 7953-7962. doi:10.1039/c3nr02800c

49. Fang, C.; Jia, H.; Chang, S.; Ruan, Q.; Wang, P.; Chen, T.; Wang, J. Energy Environ. Sci. 2014, 7, 3431-3438. doi:10.1039/c4ee01787k

50. Frens, G. Nature 1973, 241, 20-22. doi:10.1038/physci241020a0

51. Leopold, N.; Lendl, B. J. Phys. Chem. B 2003, 107, 5723-5727. doi:10.1021/jp027460u

52. Mine, E.; Hirose, M.; Nagao, D.; Kobayashi, Y.; Konno, M. J. Colloid Interface Sci. 2005, 291, 162-168. doi:10.1016/j.jcis.2005.04.077

53. Mine, E.; Hirose, M.; Kubo, M.; Kobayashi, Y.; Nagao, D.; Konno, M. J. Sol-Gel Sci. Technol. 2006, 38, 91-95. doi:10.1007/s10971-006-5855-y

54. Turevskaya, E. P.; Yanovskaya, M. I.; Turova, N. Y. Inorg. Mater. 2000, 36, 260-270. doi:10.1007/BF02757931

55. Livage, J.; Henry, M.; Sanchez, C. Prog. Solid State Chem. 1988, 18, 259-341. doi:10.1016/0079-6786(88)90005-2

56. Jiang, X.; Herricks, T.; Xia, Y. Adv. Mater. 2003, 15, 1205-1209. doi:10.1002/adma.200305105

57. Sentosun, K.; Sanz-Ortiz, M. N.; Batenburg, K. J.; Liz-Marzán, L. M.; Bals, S. Part. Part. Syst. Charact. 2015, 32, 1063-1067. doi:10.1002/ppsc.201500097

58. Anderson, W.; Kozak, D.; Coleman, V. A.; Jämting, A. K.; Trau, M. J. Colloid Interface Sci. 2013, 405, 322-330. doi:10.1016/j.jcis.2013.02.030

59. Bell, N. C.; Minelli, C.; Tompkins, J.; Stevens, M. M.; Shard, A. G. Langmuir 2012, 28, 10860-10872. doi:10.1021/la301351k

60. Fielding, L. A.; Mykhaylyk, O. O.; Armes, S. P.; Fowler, P. W.; Mittal, V.; Fitzpatrick, S. Langmuir 2012, 28, 2536-2544. doi:10.1021/la204841n 
61. Carney, R. P.; Kim, J. Y.; Qian, H.; Jin, R.; Mehenni, H.; Stellacci, F.; Bakr, O. M. Nat. Commun. 2011, 2, 335. doi:10.1038/ncomms1338

62. Krpetić, Ž.; Davidson, A. M.; Volk, M.; Lévy, R.; Brust, M.; Cooper, D. L. ACS Nano 2013, 7, 8881-8890. doi:10.1021/nn403350v

63. Kozak, D.; Anderson, W.; Vogel, R.; Chen, S.; Antaw, F.; Trau, M. ACS Nano 2012, 6, 6990-6997. doi:10.1021/nn3020322

64. Pal, A. K.; Aalaei, I.; Gadde, S.; Gaines, P.; Schmidt, D.; Demokritou, P.; Bello, D. ACS Nano 2014, 8, 9003-9015. doi:10.1021/nn502219q

65. Weatherall, E.; Willmott, G. R. Analyst 2015, 140, 3318-3334. doi:10.1039/c4an02270j

66. Zarick, H. F.; Erwin, W. R.; Boulesbaa, A.; Hurd, O. K.; Webb, J. A.; Puretzky, A. A.; Geohegan, D. B.; Bardhan, R. ACS Photonics 2016, 3 , 385-394. doi:10.1021/acsphotonics.5b00552

\section{License and Terms}

This is an Open Access article under the terms of the Creative Commons Attribution License

(http://creativecommons.org/licenses/by/4.0), which permits unrestricted use, distribution, and reproduction in any medium, provided the original work is properly cited.

The license is subject to the Beilstein Journal of

Nanotechnology terms and conditions:

(http://www.beilstein-journals.org/bjnano)

The definitive version of this article is the electronic one which can be found at: doi:10.3762/bjnano.8.208 